\section{Attention: All CIF Members}

\section{Resolutions $\mathbf{7 6 . 3}$ and $\mathbf{7 6 . 5}$}

The attention of the CIF membership is drawn to two resolutions that were discussed at the Annual General Meeting in Thunder Bay last year. Both these resolutions are likely to come before the Annual General Meeting in Vancouver this October. Your Executive Committee considers it important that you have knowledge of these beforehand, and urges you to give them some thought.

\section{Resolution 76.3}

WHEREAS the objectives of the Canadian Institute of Forestry and those of the provincial associations of professional foresters have much in common, and

WHEREAS such common objectives may frequently be pursued at the local or Section level, and

WHEREAS many foresters are members of both organizations;

Be it resolved that the Canadian Institute of Forestry be prepared to consult with the Canadian Provincial Associations of Professional Foresters that have established local sections, with a view to reaching agreement on coincidence of Section boundaries, and

Be it further resolved that such agreements be made independently with each such professional association, and

$\mathrm{Be}$ it further resolved that where and when Section boundaries coincide, the Institute encourages the conduct of joint CIF/Professional Association activities at the Section level.

This resolution was the subject of considerable debate in which a wide range of opinions were expressed. Finally a motion was passed tabling Resolution 76.3. Consequently this resolution will only be debated in Vancouver if an active member in good standing lifts it from the table during that period of our business meeting devoted to the discussion of resolutions. The Chair will not introduce the resolution.

\section{Resolution 76.5}

WHEREAS the objects of the Canadian Institute of Forestry, in part, are: to encourage a wider understanding of the problems of forestry; to improve all aspects of forestry practices in Canada; to advance the members in their knowledge of the sciences and practices of forestry; and to cultivate an esprit de corps within the profession, and
WHEREAS there is no organization in Canada including the Canadian Institute of Forestry that is able to objectively and effectively speak out and take a stance on forestry problems, in Canada necessary to meet these objectives, and

WHEREAS the forestry profession needs a full time spokesman to address and inform Canadians on forestry in Canada, and

WHEREAS the President of the Canadian Institute of Forestry is a logical spokesman but is unable to devote full time to this vital activity and may be constrained by the fact that his first responsibility is to his employer, and

WHEREAS it is impossible under the existing organization of the Institute for the President to become fully knowledgeable about Canada as a federal state with its complex and diverse economic, social, political matrix that impacts on the Canadian Forestry scene without complete involvement, and

WHEREAS many of the working groups require objectives, direction and a sense of meaning to their efforts:

Be it resolved that the President of the Canadian Institute of Forestry be seconded from his employment for a period of at least one (1) year and be hired full time at an appropriate remuneration for the purpose of conducting the affairs of the Institute and devoting his energies to being the national voice of the forestry profession in Canada, and

$\mathrm{Be}$ it further resolved that the mandate of the working groups include researching and supplying the President with information on forestry problems in Canada, and

$B e$ it further resolved that the By-laws governing the organization and activities of the Institute be changed accordingly, and

Be it further resolved that the members dues be raised by an amount required for the appropriate remuneration.

This resolution was not actually submitted before the meeting in Thunder Bay although it was debated. Rather it was presented as a notice of motion, it being the intention of the originators to formally submit it in 1977 in Vancouver. However it was a proposal of such magnitude that it was believed prudent to provide advance notice so that the membership would have the opportunity to give it the thought and time it deserved. Your Executive Committee asks you to do that now.

Neither your Executive Committee nor your Board of Directors have taken a position on either of these resolutions of this date.

\section{A. Brookman Anderson}

